ARTICLE

DOI: $10.1038 / \mathrm{s} 41467-018-05301-6$

\title{
High sensitivity organic inorganic hybrid X-ray detectors with direct transduction and broadband response
}

\author{
H.M. Thirimanne1, K.D.G.I. Jayawardena ${ }^{1}$, A.J. Parnell (1) ${ }^{2}$, R.M.I. Bandara', A. Karalasingam', S. Pani ${ }^{3}$, \\ J.E. Huerdler ${ }^{4}$, D.G. Lidzey ${ }^{2}$, S.F. Tedde ${ }^{4}$, A. Nisbet ${ }^{3,5}$, C.A. Mills $^{1}$ \& S.R.P. Silva (i) ${ }^{1}$
}

X-ray detectors are critical to healthcare diagnostics, cancer therapy and homeland security, with many potential uses limited by system cost and/or detector dimensions. Current X-ray detector sensitivities are limited by the bulk X-ray attenuation of the materials and consequently necessitate thick crystals $(\sim \mathrm{mm}-1 \mathrm{~cm})$, resulting in rigid structures, high operational voltages and high cost. Here we present a disruptive, flexible, low cost, broadband, and high sensitivity direct $\mathrm{X}$-ray transduction technology produced by embedding high atomic number bismuth oxide nanoparticles in an organic bulk heterojunction. These hybrid detectors demonstrate sensitivities of $1712 \mu \mathrm{C} \mathrm{mGy}^{-1} \mathrm{~cm}^{-3}$ for "soft" X-rays and $\sim 30$ and $58 \mu \mathrm{C} \mathrm{mGy}{ }^{-1}$ $\mathrm{cm}^{-3}$ under 6 and $15 \mathrm{MV}$ "hard" X-rays generated from a medical linear accelerator; strongly competing with the current solid state detectors, all achieved at low bias voltages ( $-10 \mathrm{~V}$ ) and low power, enabling detector operation powered by coin cell batteries.

\footnotetext{
${ }^{1}$ Department of Electrical and Electronic Engineering, Advanced Technology Institute, University of Surrey, Guildford, Surrey GU2 7XH, UK. ${ }^{2}$ Department of Physics and Astronomy, University of Sheffield, Hicks Building, Sheffield S3 7RH, UK. ${ }^{3}$ Department of Physics, University of Surrey, Guildford, Surrey GU2 7XH, UK. ${ }^{4}$ Siemens Healthineers GmbH, Technology Centre, 91058 Erlangen, Germany. ${ }^{5}$ Department of Medical Physics, Royal Surrey County Hospital NHS Foundation Trust, Egerton Road, Guildford GU2 7XX, UK. These authors contributed equally: H.M. Thirimanne, K.D.G.I. Jayawardena. Correspondence and requests for materials should be addressed to S.R.P.S. (email: s.silva@surrey.ac.uk)
} 
X -rays are widely used in homeland security, therapeutic and diagnostic healthcare and industrial process control (e.g. pharmaceuticals) with each application necessitating specific detector requirements ${ }^{1}$. For example, direct conversion detectors based on materials such as amorphous selenium ${ }^{2}$ are currently used in mammography, but are limited by their low Xray attenuation for energies higher than $50 \mathrm{keV}$. Detectors based on p-type silicon with its high radiation-damage resistance are used in radiotherapy for dose measurement or beam imaging ${ }^{3}$. However, their propensity to damage from accumulated dose and drift due to environmental effects makes these less useful for beam calibration ${ }^{4}$. High-quality single crystal $\mathrm{Cd}(\mathrm{Zn}) \mathrm{Te}^{5}$ is used for homeland security screening, but suffers from being limited to small dimensions, high cost, charge carrier trapping and highvoltage operation $(>500 \mathrm{~V})$. Similarly, X-ray detection in the nondestructive evaluation sector is currently dominated by CsI (Tl) scintillator screens coupled to a-Si which, despite their high stopping power and spatial resolution, are limited to sizes less than $60 \times 60 \mathrm{~cm}^{2}$. Therefore, there is a demand for broadband, high sensitivity, low-cost radiation detectors, which current inorganic detectors fail to fulfil.

Organic semiconductors can be fabricated over large areas in a flexible format, enabling conformability to complex structures at low cost and are now commercialized for photovoltaics, displays etc $^{6}$. There is increasing attention given to organic photodetectors for $\mathrm{X}$-ray detection ${ }^{7,8}$. This often involves the coupling of scintillator screens with organic photodiodes ${ }^{9}$, insertion of highatomic number $(Z)$ nanoparticles $(\mathrm{NPs})^{10}$, quantum dots ${ }^{11}$ or scintillator particles into organic diodes ${ }^{12}$, or the use of thin film organic semiconductors ${ }^{8}$ or crystals $^{13}$. Of these, the use of X-ray scintillators is often preferred as this enables the already mature organic photodetector technologies to be adapted for X-ray detection. However, the absorption of light by the organic semiconductor forms bound electron-hole pairs (excitons), which need to be dissociated ${ }^{12}$ resulting in significant losses, limiting detector sensitivity as opposed to a direct conversion process.

Here, we introduce a broadband, direct, X-ray detector concept based on a thin film, hybrid semiconductor diode consisting of an organic bulk heterojunction $(\mathrm{BHJ})$-bismuth oxide $\left(\mathrm{Bi}_{2} \mathrm{O}_{3}\right)$ NP composite. These direct $\mathrm{X}$-ray detectors demonstrate high sensitivities of $1712 \mu \mathrm{C} \mathrm{mGy} \mathrm{cm}^{-1}$ under $50 \mathrm{kV}$ soft X-rays and $\sim 30$ and $58 \mu \mathrm{CmGy}^{-1} \mathrm{~cm}^{-3}$ under 6 and $15 \mathrm{MV}$ hard $\mathrm{X}$-rays. Furthermore, we also demonstrate a flexible detector based on the same device concept which offer a high sensitivity of $280 \mu \mathrm{C} \mathrm{mGy} \mathrm{m} \mathrm{cm}^{-3}$. More importantly, these sensitivities are achieved at $-10 \mathrm{~V}$.

\section{Results}

$\mathrm{X}$-ray response of $\mathrm{BHJ}-\mathrm{NP}$ detectors. The device compromises of a diode architecture where the BHJ-NP composite is sandwiched between indium tin oxide (ITO) and aluminium (Al) electrodes (Fig. 1a). Here, the introduction of the $\mathrm{Bi}_{2} \mathrm{O}_{3}(Z=83$ for $\mathrm{Bi}$ ) is utilised to increase the $\mathrm{X}$-ray attenuation ${ }^{14}$. We have chosen $\mathrm{Bi}_{2} \mathrm{O}_{3}$ from the many metal oxides available based on its direct conversion of $\mathrm{X}$-rays and lower environmental impact and health risks when compared to, for example, high $Z \mathrm{~Pb}$-based semiconductors. Given its existing use as a non-toxic dental material such as in the case of hydraulic silicate cements ${ }^{15}$ with an opacity to X-rays makes it an ideal candidate for our application. a

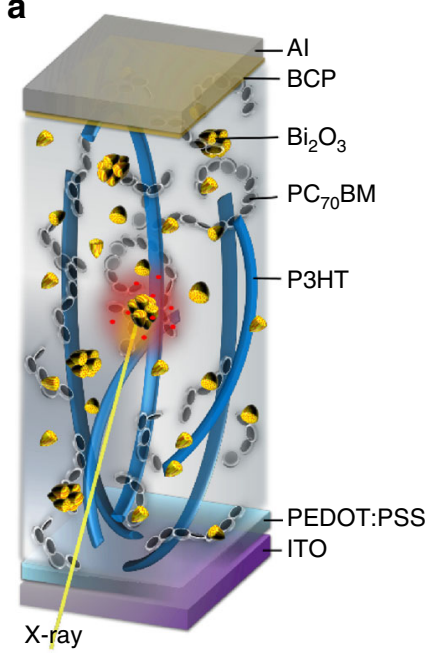

C

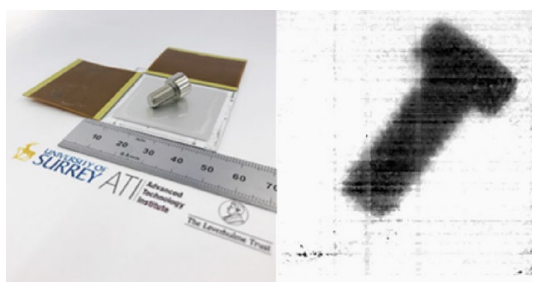

b

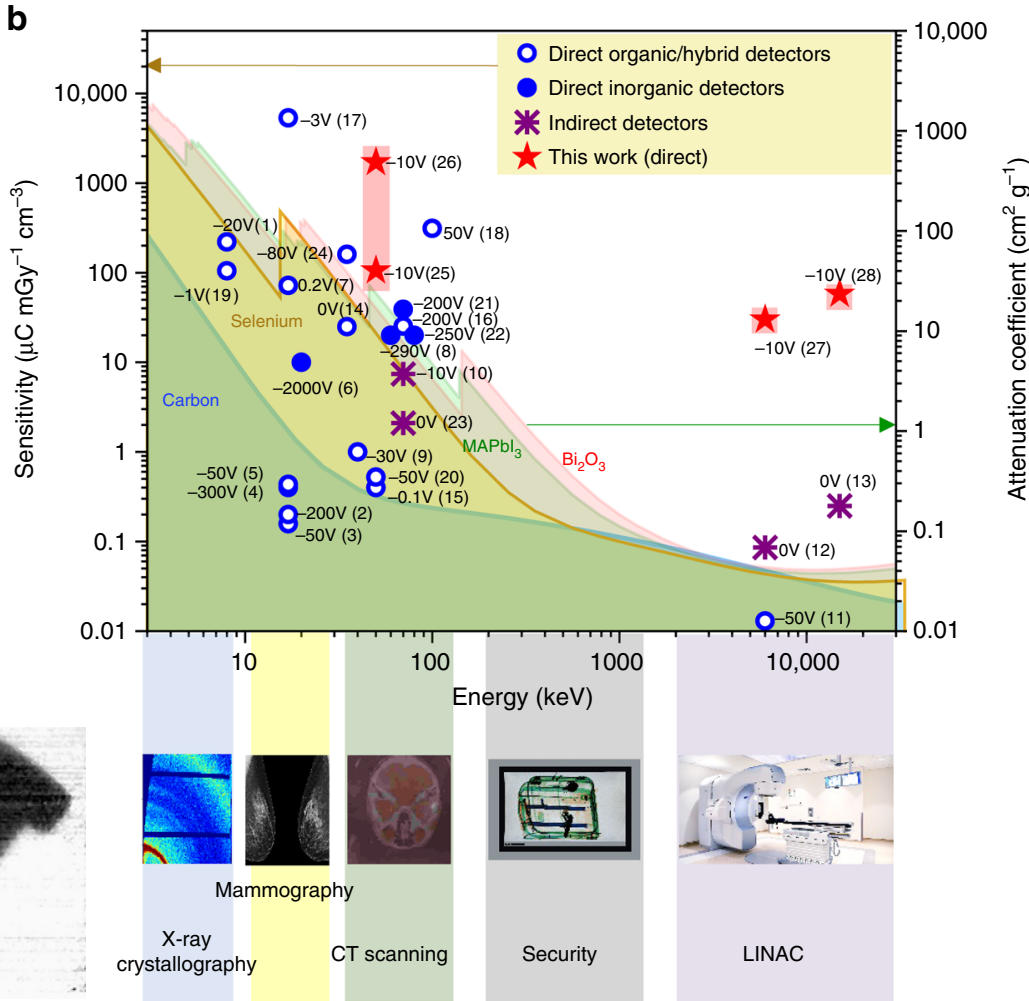

Fig. 1 X-ray detector overview. a Device schematic structure. b Performance comparison of current solid state X-ray detectors- $(1)^{13},(2)^{10},(3)^{36},(4)^{37}$, $(5)^{38},(7)^{8},(9)^{11},(11)^{3},(14)^{39},(15)^{40},(16)^{7},(17)^{41},(18)^{42},(19)^{43},(20)^{44}$, and $(24)^{20}$ are direct detectors, $(6)^{45},(8)^{46},(21)^{7,47}$ and $(22)^{48}$ are inorganic detectors, and $(10)^{12},(12)^{9},(13)^{25}$ and $(23)^{49}$ are indirect detectors-with the technology developed in this work- $(25) \mathrm{Bi}_{2} \mathrm{O}_{3}-40,(26) \mathrm{Bi}_{2} \mathrm{O}_{3}-80,(27)$ $\mathrm{Bi}_{2} \mathrm{O}_{3}-40$ and (28) $\mathrm{Bi}_{2} \mathrm{O}_{3}-40$. The operating voltage is given adjacent to each data point. The total attenuation coefficient values of carbon, selenium, methylammonium lead iodide $\left(\mathrm{MAPb}_{3}\right)$ and $\mathrm{Bi}_{2} \mathrm{O}_{3}$ are given as shaded areas showing the previous limits to detector technology based only on bulk attenuation processes. c An X-ray imager based on the hybrid X-ray detector and $70 \mathrm{kV}$ X-ray image of a bolt taken using the X-ray imager 
Regioregular poly(3-hexylthiophene-2,5-diyl) (P3HT) and [6,6]Phenyl $\mathrm{C}_{71}$ butyric acid methyl ester $\left(\mathrm{PC}_{70} \mathrm{BM}\right)$ were selected as the $\mathrm{BHJ}$ system. The formation of nanoscale diodes throughout the volume of the BHJ, in close proximity to the NPs leads to an in-built depletion region, with local electric fields as high as $\sim 200 \mathrm{~V} \mu \mathrm{m}^{-116}$, which has been experimentally quantified with Fourier-transform IR-absorption spectroscopy for the P3HT:PCBM system. This is further enhanced by dielectric inhomogeneities in the material ${ }^{17,18}$. The above factors, in combination with the high crystallinity of $\mathrm{P} 3 \mathrm{HT}: \mathrm{PC}_{70} \mathrm{BM}$ enables efficient electron and hole extraction from the entirety of the depleted active layer under low reverse-bias voltages $(<10 \mathrm{~V})$. The above factors enable an X-ray detector with high sensitivity that strongly competes with all existing solid state X-ray detector technologies, under low voltages as well as over a broad X-ray energy range (Fig. $1 \mathrm{~b}$ and Supplementary Figure 1) with potential applications in X-ray imaging as shown from a prototype imager developed through this work (Fig. 1c).

For optimisation of the detector, the NP loading within the device active volume was increased in order to increase the $\mathrm{X}$-ray attenuation by varying the $\mathrm{Bi}_{2} \mathrm{O}_{3}$ content in the parent solution $\left(0,10,20,30,40,50,60,70\right.$ and $80 \mathrm{mg} \mathrm{ml}^{-1}: \mathrm{X} \mathrm{mg} \mathrm{ml}^{-1}$ is noted as $\left.\mathrm{Bi}_{2} \mathrm{O}_{3}-\mathrm{X}\right)$. It is worth to note that the highest NP-loaded device which could be fabricated using the given procedure is $\mathrm{Bi}_{2} \mathrm{O}_{3}-80$, due to the formation of cracks during the annealing process at higher loadings beyond $\mathrm{Bi}_{2} \mathrm{O}_{3}-80$. However, with the appropriate selection of the organic bulk heterojunction and with tuning of the solvent used, much higher $\mathrm{Bi}_{2} \mathrm{O}_{3}$-loaded device fabrication maybe possible. Assuming a periodic structure for the NPs within the $\mathrm{BHJ}$, this enables the unit cell dimensions to be reduced from $72 \mathrm{~nm}$ for $\mathrm{Bi}_{2} \mathrm{O}_{3}-40$ to $64 \mathrm{~nm}$ for $\mathrm{Bi}_{2} \mathrm{O}_{3}-80$ (Supplementary Figure 2 and Supplementary Note 1). The detectors with thicknesses of $\sim 10-30 \mu \mathrm{m}$ (Supplementary Figure 3) demonstrate dark current densities in the range of $10^{-4}\left(\mathrm{Bi}_{2} \mathrm{O}_{3}-80\right)$ to $10^{-6}$ $\left(\mathrm{Bi}_{2} \mathrm{O}_{3}-0\right) \mathrm{A} \mathrm{cm}^{-2}$ at $-10 \mathrm{~V}$, and $\sim 1$ and $\sim 40 \mathrm{nA} \mathrm{cm}^{-2}$ under 0 and $-1 \mathrm{~V}$, respectively (Supplementary Figure $4 \mathrm{a}$ ). We note recent work in the literature where the dark current can be tuned to meet industrial requirements through appropriate BHJ selection as a promising route for further improvements ${ }^{19}$.

Visible light photocurrent measurements are a useful tool in determining whether NP incorporation disrupts the $\mathrm{BHJ}$ phase separation thereby impeding charge transport. The lack of significant variation in the visible light photocurrent response for different $\mathrm{Bi}_{2} \mathrm{O}_{3}$ loadings indicates that the phase separation within the $\mathrm{BHJ}$ remains undisturbed (Supplementary Figure $4 \mathrm{~b}$ ). The X-ray photocurrent response of the detectors tested under a $50 \mathrm{kV} \mathrm{X}$-ray source at $-10 \mathrm{~V}$ bias, demonstrates a linear increase with increasing NP loading from $\mathrm{Bi}_{2} \mathrm{O}_{3}-0$ to $\mathrm{Bi}_{2} \mathrm{O}_{3}-40$ (Fig. 2a, b), followed by a non-linear increase for $\mathrm{Bi}_{2} \mathrm{O}_{3}-60$ and upwards. The $\mathrm{X}$-ray sensitivity $(S)$ depends on the amount of X-rays stopped, which depends on both the device cross section and its thickness, and hence, the sensitivity of the detector is calculated by:

$$
S=\frac{\int\left[I_{\mathrm{X}-\mathrm{ray}}(t)-I_{\mathrm{dark}}\right] \mathrm{d} t}{D \times V}
$$

where, $I_{\mathrm{X} \text {-ray }}$ and $I_{\mathrm{dark}}$ are the current under X-ray irradiation and in the dark respectively, $D$ is the dose and $V$, the detector volume. For the detectors studied herein, $S$ increases from $41\left(\mathrm{Bi}_{2} \mathrm{O}_{3}-10\right)$ to $1712\left(\mathrm{Bi}_{2} \mathrm{O}_{3}-80\right) \mu \mathrm{CmGy}^{-1} \mathrm{~cm}^{-3}$ (Fig. 2c). We note that Ciavatti et al. ${ }^{20}$ recently reported $\mathrm{Bi}_{2} \mathrm{O}_{3}$ NP-loaded $\mathrm{PFO}$ polymerbased diodes for X-ray detection where the highest $S$ observed was $160 \mu \mathrm{C} \mathrm{mGy}^{-1} \mathrm{~cm}^{-3}$ which is slightly higher than the $S$ of $\mathrm{Bi}_{2} \mathrm{O}_{3}-40\left(105 \mu \mathrm{CmGy}^{-1} \mathrm{~cm}^{-3}\right)$. Despite the similarity in magnitude of these $S$ values, we note that the former work employed a $35 \mathrm{kV}$ Mo target as opposed to the $50 \mathrm{kV} \mathrm{W}$ target used in this work. As stated and shown schematically (Fig. 1b), the X-ray attenuation significantly improves by approximately one order of magnitude as the X-ray spectrum shifts to lower energies which is expected to result in the nearly similar $S$ values for the $\mathrm{Bi}_{2} \mathrm{O}_{3}$ NP-loaded PFO polymer-based diodes and the $\mathrm{Bi}_{2} \mathrm{O}_{3}-40$ diodes. We expect the $S$ values for the $\mathrm{Bi}_{2} \mathrm{O}_{3}-40$ diodes to be higher if measured under low $\mathrm{kV}$ sources due to the enhanced X-ray attenuation as a result of increase in the mass attenuation, especially under high NP loading as well as due to the use of the BHJ thick films which enables a more balanced carrier transport. The combination of the direct conversion of $\mathrm{X}$ ray photons to charge carriers as well as the very high electric fields at the hybrid interfaces adjacent to the NPs, is a necessity for the much improved currents observed. The number of charges extracted (as calculated from the X-ray photocurrent response) vs. the number of X-ray photons absorbed (calculated based on the bulk X-ray attenuation model-Supplementary Figure 5) indicates $\mathrm{a} \sim \times 10^{3}$ enhancement in charge collection efficiency (CCE) than expected from the bulk attenuation model for $\mathrm{Bi}_{2} \mathrm{O}_{3}$ 10 to $\mathrm{Bi}_{2} \mathrm{O}_{3}-70$, and a $\sim \times 10^{5} \mathrm{CCE}$ increase for $\mathrm{Bi}_{2} \mathrm{O}_{3}-80$ (Fig. 2d). In comparison, the $\mathrm{Bi}_{2} \mathrm{O}_{3}-0$ system shows nearly an order of magnitude lower CCE.

The voltage dependence of the BHJ-NP X-ray detectors display a linear behaviour for low reverse-bias voltages $(<10 \mathrm{~V})$ with sensitivity of $0.13 \mu \mathrm{C} \mathrm{mGy}^{-1} \mathrm{~cm}^{-3}$ for low-voltage bias $(-2.5 \mathrm{~V})$ indicating its suitability for portable, real time radiation monitoring, powered by coin cell batteries or by indoor lighting. An X-ray photocurrent response was also obtained under shortcircuit conditions (at $0 \mathrm{~V}$ ) (Fig. 2e, f). A non-linear X-ray current response is observed for higher biases due to space charge-limited conduction with a three orders of magnitude improvement observed under $-50 \mathrm{~V}$. Further, as the voltage increases, the Xray response increases while retaining the dark currents of 6 and $41 \mathrm{nA} \mathrm{cm}^{-2}$ (at -0.1 and $-1 \mathrm{~V}$, respectively). The sensitivity of $0.13 \mu \mathrm{C} \mathrm{mGy}{ }^{-1} \mathrm{~cm}^{-3}$ under reverse-bias voltages of $<3 \mathrm{~V}$ indicates the suitability of this technology for portable, real time radiation monitoring, with power provided by coin cell batteries or by indoor light harvesting photovoltaic cells.

Figure $2 \mathrm{~g}$ shows that the rise time (to $90 \%$ of the maximum signal) and the fall time (to $10 \%$ of the maximum signal) increases as the $\mathrm{Bi}_{2} \mathrm{O}_{3}$ loading increases. The slow response under reverse bias is due to the trap states generally present in metal oxide surfaces ${ }^{21}$ and between the metal/semiconductor interfaces $^{22}$. Further development in passivation of these defects is expected to significantly improve the response time of these detectors. We note that the rise and fall times are significantly reduced to less than $100 \mathrm{~ms}$ when the diodes are operated under $0 \mathrm{~V}$. Another important detector metric is the linearity of the detector response, which enables the rapid determination of the X-ray dose, especially for dosimetry. Supplementary Figure 6 shows a representative $\mathrm{X}$-ray photocurrent response curve for the $\mathrm{Bi}_{2} \mathrm{O}_{3}-40$ device in which an excellent linear response is observed.

An area of significant interest of $\mathrm{X}$-ray imaging is the development of flexible, conformable imagers, a feature not enabled by current digital flat panel X-ray detectors. In order to evaluate the performance of the $\mathrm{BHJ}-\mathrm{NP}$ detectors under deformation, we fabricated the optimized $\mathrm{Bi}_{2} \mathrm{O}_{3}-40$ X-ray detectors on a flexible substrate. The detectors demonstrate a nearly unchanged, high sensitivity of $280 \mu \mathrm{C} \mathrm{mGy}-1 \mathrm{~cm}^{-3}$ (Fig. 2h) both prior to, and after undergoing 10 bend cycles of $\sim 3 \mathrm{~mm}$ bend radius (Fig. 2i). A slight variation in the rise and decay constant was observed possibly due to the poor mechanical properties of the contact materials or the use of a fullerene-based acceptor, as opposed to an all polymer-based $\mathrm{BHJ}$, which might have deteriorated the mechanical properties of the $\mathrm{BH}^{23}$. Based on our concept of hybrid organic-inorganic materials for 
a

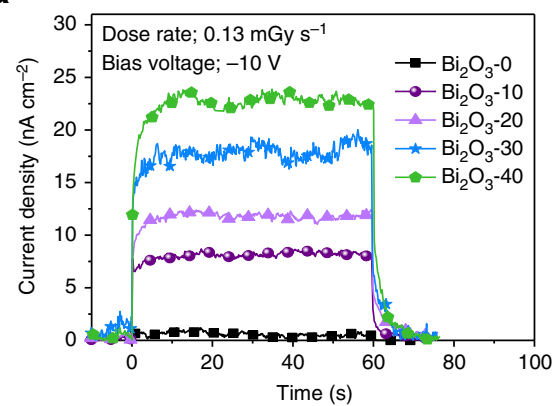

d

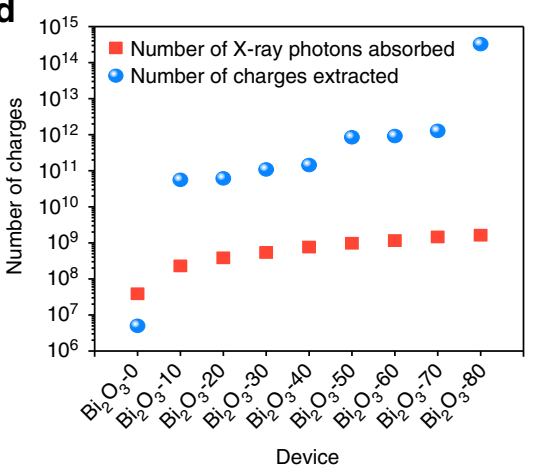

g

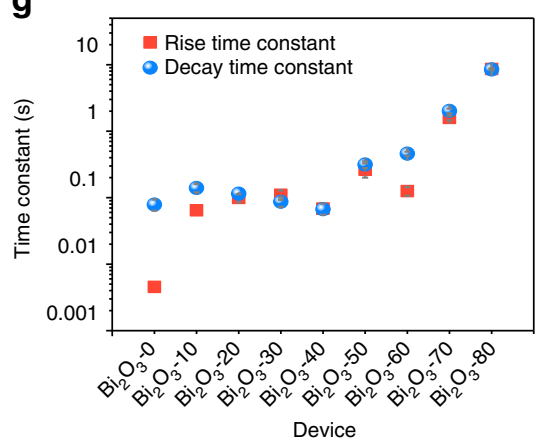

b
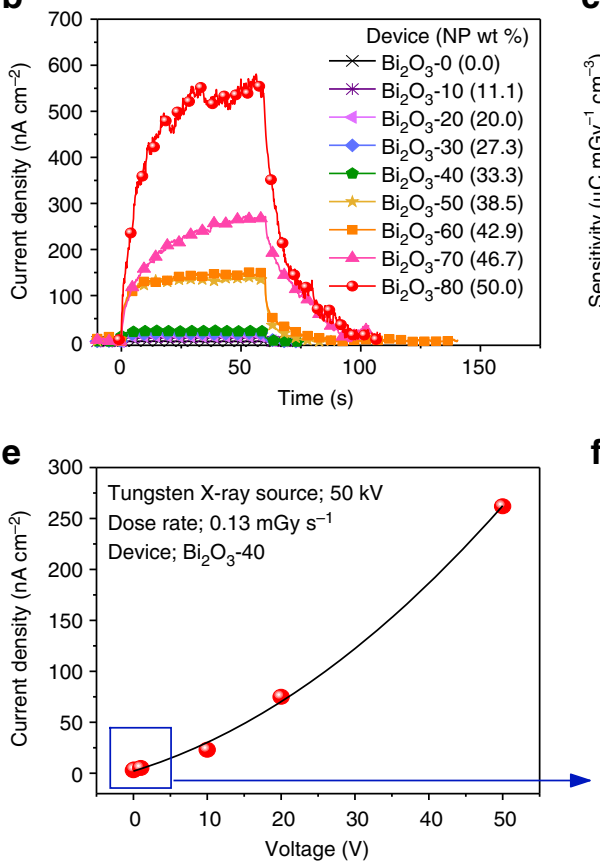

h

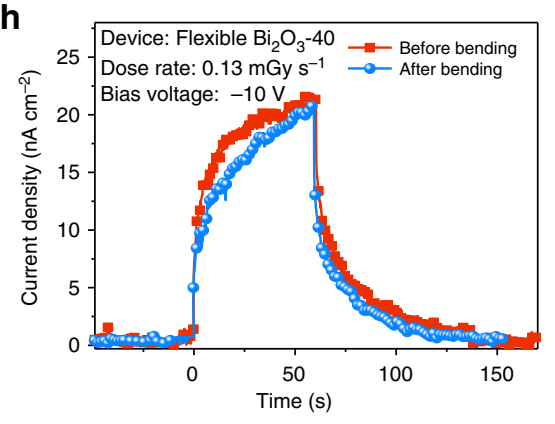

C

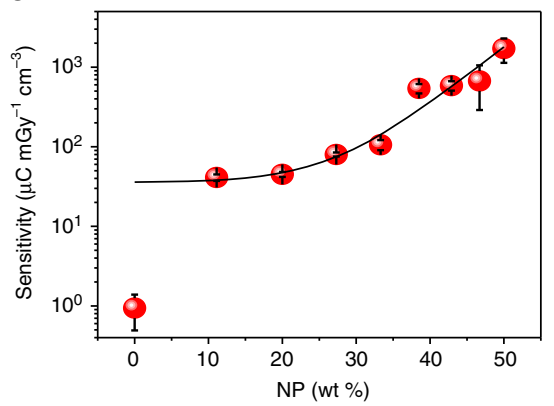

f

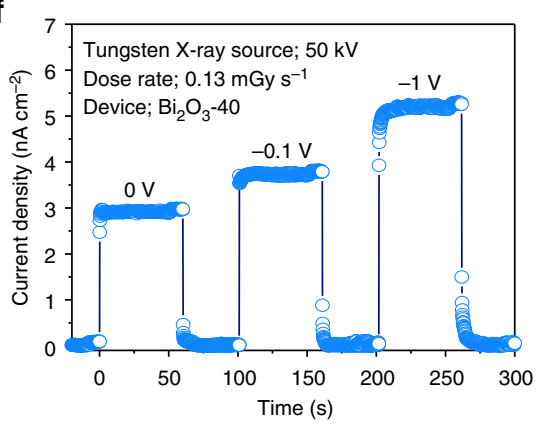

i

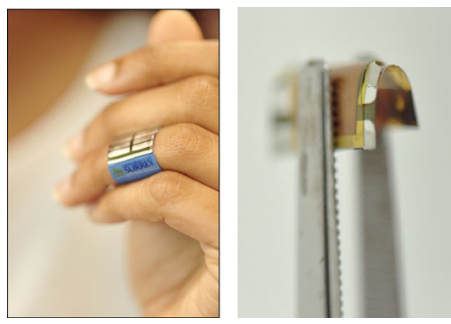

Fig. 2 Detector performance under X-ray irradiation. a X-ray photocurrent densities for devices with different $\mathrm{Bi}_{2} \mathrm{O}_{3}$ loadings from $\mathrm{Bi}_{2} \mathrm{O}_{3}-0$ to $\mathrm{Bi}_{2} \mathrm{O}_{3}-40$ and b from $\mathrm{Bi}_{2} \mathrm{O}_{3}-\mathrm{O}$ to $\mathrm{Bi}_{2} \mathrm{O}_{3}-80$. c Averaged sensitivity values for six devices and the error bars represent the range of the sensitivity values. $\mathbf{d}$ Comparison between number of $\mathrm{X}$-ray photons absorbed by each device and the number of charges extracted. $\mathbf{e}$ The voltage dependence of the $\mathrm{Bi}_{2} \mathrm{O}_{3}-40$ device, f X-ray photocurrent response of the $\mathrm{Bi}_{2} \mathrm{O}_{3}-40$ detector under $0,-0.1$ and $-1 \mathrm{~V}$ biases. $\mathbf{g}$ Rise and decay time constants (the error bars represent the standard error shown with respect to the fitted curves) for detectors with increasing $\mathrm{Bi}_{2} \mathrm{O}_{3}$ loadings under $-10 \mathrm{~V}$ bias. $\mathbf{h} \mathrm{X}$-ray photocurrent response before and after bending for a flexible $\mathrm{Bi}_{2} \mathrm{O}_{3}-40$ device. $\mathbf{i}$ A prototype $\mathrm{X}$-ray detector integrated into a plaster and detector bend radius $(0.3 \mathrm{~cm})$

X-ray detectors, many new and more suitable combinations can now be examined for future detectors.

A major potential application for such conformable X-ray detectors is, as dosimeters to be used in combination with a medical linear accelerator (LINAC), which are widely used for cancer therapy. The use of a conformable dosimeter as an in vivo detector on the surface of the patient or within a body cavity is highly likely to enable a more accurate X-ray delivery to patients thereby minimizing additional normal tissue damage as well as potential risks related to secondary cancer induction. A recent review in this field has recommended that all the radiotherapy treatments with curative intent should be verified through in vivo dose measurements in combination with pre-treatment checks ${ }^{24}$. As such, our optimized $\mathrm{Bi}_{2} \mathrm{O}_{3}-40$ detectors were tested under 6 and $15 \mathrm{MV}$ X-rays from a medical LINAC (Fig. 3). Under a $114 \mu \mathrm{Gy} \mathrm{s} \mathrm{s}^{-1}$ dose rate and $-10 \mathrm{~V}$ reverse bias, the detector delivered a sensitivity of 30 and $58 \mu \mathrm{C} \mathrm{mGy}^{-1} \mathrm{~cm}^{-3}$ for 6 and 15 MV X-rays, respectively. These values are nearly $\times 100$ higher than those reported for organic photodetectors tested under 6 and
15 MV LINAC X-rays using $\mathrm{Gd}_{2} \mathrm{O}_{2} \mathrm{~S}$ : $\mathrm{Tb}$ as a scintillator ${ }^{9,25}$ therefore demonstrating that the $\mathrm{BHJ}-\mathrm{NP}$ architecture developed here is a promising dosimeter concept for accurate dose delivery. It is noted that the $\mathrm{Bi}_{2} \mathrm{O}_{3}-40$ device did not show a noticeable performance degradation when exposed to 6 and $15 \mathrm{MV}$ X-rays over several X-ray exposure cycles which results in a cumulative exposure dose of $0.15 \mathrm{~Gy}$.

Structural characterisation. We examined the impact of the $\mathrm{Bi}_{2} \mathrm{O}_{3} \mathrm{NP}$ inclusion on the structural properties of the P3HT: $\mathrm{PC}_{70} \mathrm{BM}$ through Grazing Incidence Wide Angle X-Ray Scattering (GI-WAXS) (Fig. 4a). While the intensity of the $\mathrm{Bi}_{2} \mathrm{O}_{3}$ diffraction rings increases with increasing $\mathrm{Bi}_{2} \mathrm{O}_{3}$ loading, a high $\mathrm{P} 3 \mathrm{HT}$ crystallinity is also observed for all films, peaking at $\mathrm{Bi}_{2} \mathrm{O}_{3}-40$, with a slight reduction in the $\mathrm{Bi}_{2} \mathrm{O}_{3}-60$ to $\mathrm{Bi}_{2} \mathrm{O}_{3}-80$ devices. Further structural characterisation is explained in Supplementary Figures 7, 8 and Supplementary Note 2, 3. 


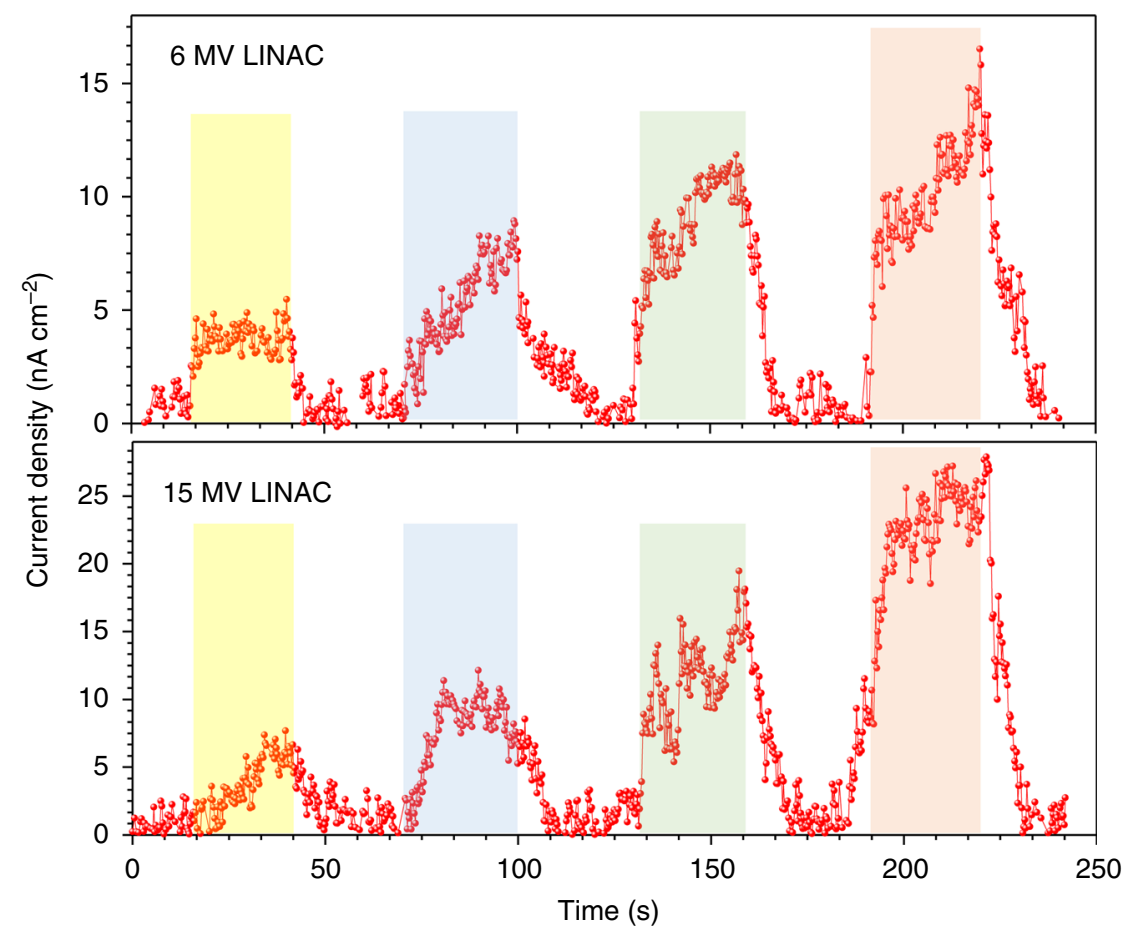

Fig. 3 Hard X-ray irradiation. Response of a $\mathrm{Bi}_{2} \mathrm{O}_{3}-40$ device under linear accelerator (LINAC) generated 6 and $15 \mathrm{MV}$ X-rays, the consecutive peaks represent the response to dose rates of $114,227,340$ and $454 \mu \mathrm{Gy} \mathrm{s} \mathrm{s}^{-1}$

a

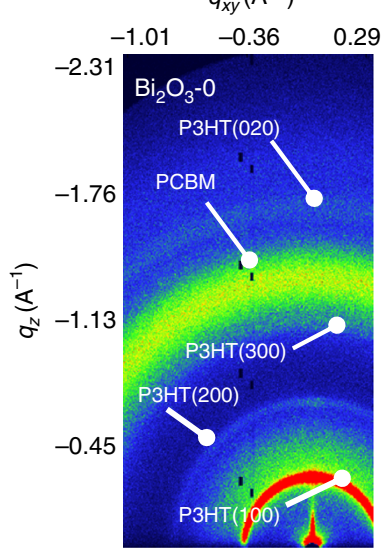

$q_{x y}\left(\mathrm{~A}^{-1}\right)$

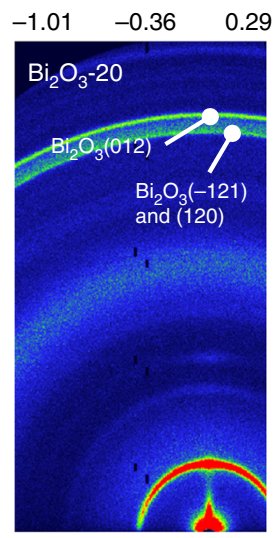

$q_{x y}\left(\mathrm{~A}^{-1}\right)$

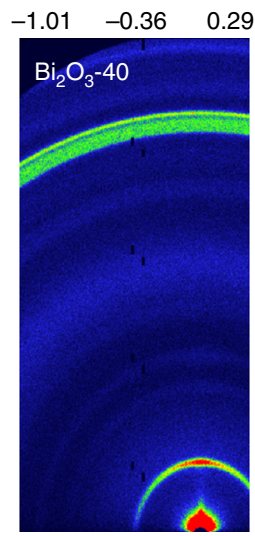

$q_{x y}\left(\mathrm{~A}^{-1}\right)$

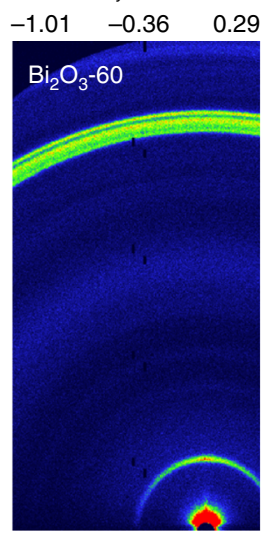

$q_{x y}\left(\mathrm{~A}^{-1}\right)$

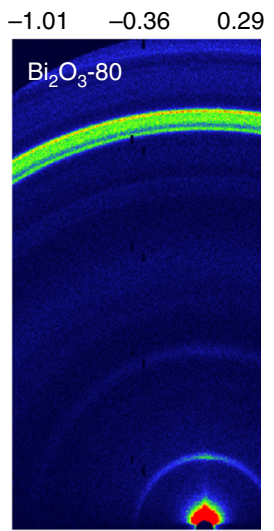

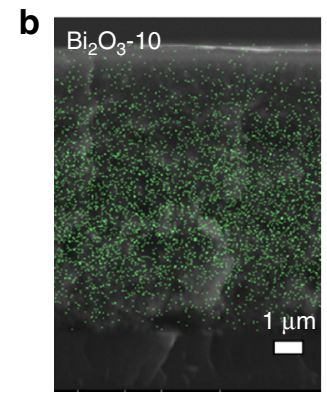
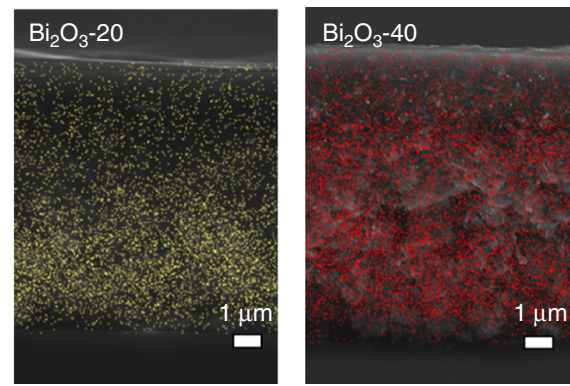

Fig. 4 X-ray detector structural characterisation. a Grazing incidence wide angle X-ray scattering images of $\mathrm{Bi}_{2} \mathrm{O}_{3}-\mathrm{O}_{2}, \mathrm{Bi}_{2} \mathrm{O}_{3}-2 \mathrm{O}, \mathrm{Bi}_{2} \mathrm{O}_{3}-40, \mathrm{Bi}_{2} \mathrm{O}_{3}-60$ and $\mathrm{Bi}_{2} \mathrm{O}_{3}-80$. Here, the position of the poly (3-hexylthiophene-2,5-diyl) (P3HT), [6,6]-Phenyl $\mathrm{C}_{71}$ butyric acid methyl ester (PCBM) and bismuth oxide ( $\mathrm{Bi}_{2} \mathrm{O}_{3}$ ) resultant peaks are indicated. $\mathbf{b}$ Scanning electron microscopy cross sections of $\mathrm{Bi}_{2} \mathrm{O}_{3}-10, \mathrm{Bi}_{2} \mathrm{O}_{3}-20$ and $\mathrm{Bi}_{2} \mathrm{O}_{3}-40$ overlaid with energy dispersive $\mathrm{X}$-ray spectroscopy imaging of the $\mathrm{Bi}_{2} \mathrm{O}_{3}$ nanoparticles (false coloured for clarity) 

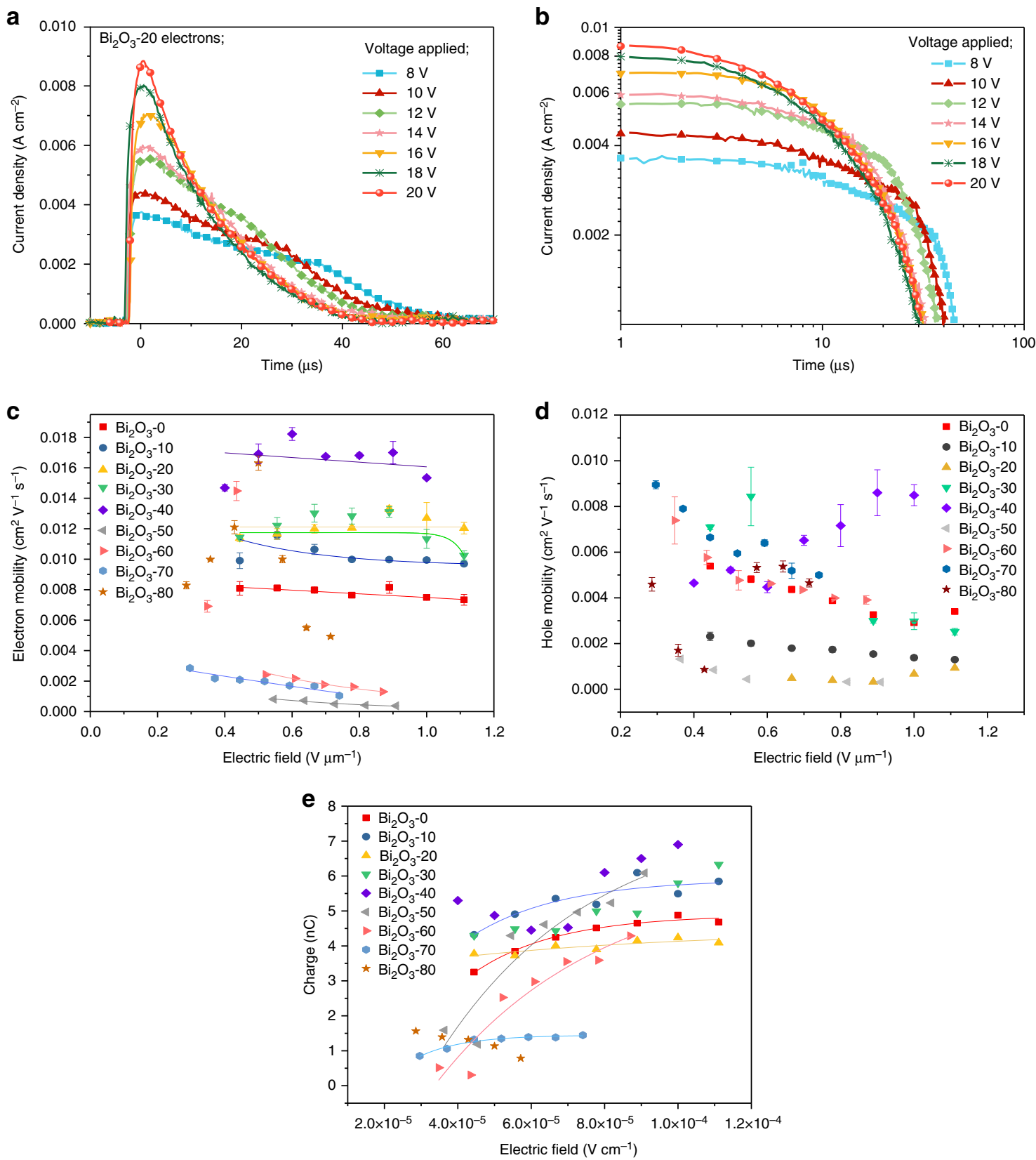

Fig. 5 Charge transport analysis. a Time-of-flight transients of electrons for the $\mathrm{Bi}_{2} \mathrm{O}_{3}-20$ device for the applied reverse-bias voltages from 8 to $20 \mathrm{~V}$. b The double logarithmic plot of the time of flight transient presented in $\mathbf{a}$. Electric field dependency of $\mathbf{c}$ electron mobility (data have been fitted to show the mobility dependency under the electric field) and $\mathbf{d}$ hole mobility of devices from $\mathrm{Bi}_{2} \mathrm{O}_{3}-\mathrm{O}$ to $\mathrm{Bi}_{2} \mathrm{O}_{3}-80$. Here, the error bars represent the range of three measurements carried out under each condition. e The collected electron charge for different devices based on a fit to the Hecht equation

Energy dispersive X-ray analysis carried out on the BHJ-NP film cross sections (Fig. 4b) shows a uniform $\mathrm{Bi}_{2} \mathrm{O}_{3} \mathrm{NP}$ distribution throughout the device thickness, indicating a homogeneous distribution of NPs and minimal dead volume without any NP sedimentation unlike previous reports ${ }^{10}$. Such distribution of the NPs offer an efficient X-ray to charge direct conversion, throughout the entirety of the device thickness. SEM and atomic force microscopy topographical analysis (Supplementary Figure 9) of the films suggests NP aggregation on the film surfaces which we have previously reported to enable efficient charge extraction through enhancements in the electric field via metal electrode structuring 26 .
Charge transport analysis. Transport of both electrons and holes was analysed by photo-induced time-of-flight (TOF), a technique widely used to measure the charge carrier transport in various low mobility semiconductors ${ }^{27}$. The mobility $(\mu)$ of the charges is determined from ${ }^{28} \mu=d^{2} /\left(t_{\text {trans }} \times V\right)$ where $d$ is the sample thickness and $V$ is the biased voltage. Figure $5 \mathrm{a}$ and $\mathrm{b}$ gives an example of TOF characteristics for electrons in a $\mathrm{Bi}_{2} \mathrm{O}_{3}-20$ device. Calculation of the carrier mobilities from the TOF transients indicates balanced electron and hole mobilities of $\sim 10^{-3} \mathrm{~cm}^{2} \mathrm{~V}^{-1} \mathrm{~s}^{-1}$, with minor variation occurring for different electric fields (Fig. $5 c$, d). These values are comparable to those observed for thinner $\mathrm{P} 3 \mathrm{HT}: \mathrm{PC}_{70} \mathrm{BM}$ photovoltaic devices ${ }^{29}$. The $\mathrm{Bi}_{2} \mathrm{O}_{3}-40$ device exhibits the highest charge carrier mobility, 
which is in agreement with the high crystallinity observed in the GI-WAXS as explained previously, as well as through DSC given in Supplementary Information 8 where a high crystallinity in excess of $45 \%$ is observed.

An important point for consideration in the development of $\mathrm{X}$ ray detectors is their CCE, described by the Hecht equation ${ }^{14}$;

$$
Q=Q_{0}\left\{\frac{\mu_{\mathrm{h}} \tau_{\mathrm{h}} E}{d}\left[1-\exp \left(-\frac{x}{\mu_{\mathrm{h}} \tau_{\mathrm{h}} E}\right)\right]+\frac{\mu_{\mathrm{e}} \tau_{\mathrm{e}} E}{d}\left[1-\exp \left(-\frac{d-x}{\mu_{\mathrm{e}} \tau_{\mathrm{e}} E}\right)\right]\right\}
$$

Here, $Q$ and $Q_{0}$ are the number of charges extracted and generated respectively at a distance $x$ from the anode, $E$ is the electric field and $\mu_{\mathrm{h}}, \mu_{\mathrm{e}}, \tau_{\mathrm{h}}$ and $\tau_{\mathrm{e}}$ are the hole and electron mobilities and transit times, respectively. Figure $5 \mathrm{e}$ exhibits the collected electron charge for different devices with a fit for the Hecht equation. For the BHJ-NP detectors, the CCE of electrons and holes separately are $\sim 63 \%$ with relatively similar $\mu \tau$ product of $\mu \tau \approx 10^{-7} \mathrm{~cm}^{2} \mathrm{~V}^{-1}$.

Origins of high sensitivity. As discussed previously, a thousandfold increase in charges extracted is observed with respect to the absorbed X-rays for $\mathrm{Bi}_{2} \mathrm{O}_{3}-10$ to $\mathrm{Bi}_{2} \mathrm{O}_{3}-70$ devices which increases to $\sim \times 10^{5}$ for $\mathrm{Bi}_{2} \mathrm{O}_{3}-80$ devices (Fig. 2d). An important effect for enhanced sensitivity is impact ionization due to hot $\mathrm{X}$-ray photoelectrons (PEs) and holes which enables $\sim 10^{3}$ free carriers to be generated per photon ${ }^{30}$. However, the CCE of 63\% points towards the possibility to an additional mechanism for sensitivity enhancement. One contributing factor towards this enhancement is photoconductivity gain, which results from trapping either electrons or holes ${ }^{14}$. The emergence of rise decay times well exceeding $100 \mathrm{~ms}$ from the device $\mathrm{Bi}_{2} \mathrm{O}_{3}-50$ upwards suggests photoconducting gain as a possible sensitivity enhancement mechanism for $\mathrm{Bi}_{2} \mathrm{O}_{3}-50$ devices and upwards. However, the $<100 \mathrm{~ms}$ rise times for the lower NP loading is indicative of a different gain mechanism that enables fairly high rise and decay times to be observed.

In astrophysical environments, it is well known that dust and ice NPs efficiently scatter X-rays due to their grain geometric sizes being on the same scale as the photon wavelength ${ }^{31,32}$. In such studies, the classical Mie model is used as an approximation in determining differential and total scattering cross sections for nano-sized particles ${ }^{32}$. Mie-scattering results when electromagnetic radiation (EMR) interacts with particles with dimensions larger than the EMR wavelength. Due to the sub-nanometre wavelength of X-rays, NPs are extremely efficient Mie scatters of X-rays where the ratio of scattered X-ray intensity $I_{s}(\lambda)$, to the irradiated X-ray intensity $I_{\mathrm{R}}(\lambda)$, can be found through ${ }^{33}$,

$$
\frac{I_{\mathrm{S}}(\lambda)}{I_{\mathrm{R}}(\lambda)}=\int_{r_{\mathrm{d}}}^{R_{\mathrm{o}}} \int_{0}^{\pi} \int_{0}^{2 \pi} \sin \theta \mathrm{d} \theta \mathrm{d} \varphi \mathrm{d} r \int_{a_{\min }}^{a_{\max }} \frac{\partial n(r, a)}{\partial a} \frac{|f(\lambda, \theta, a)|}{1+\frac{r^{2}}{R^{2}}-2 \frac{r}{R}} \mathrm{~d} a
$$

where $R$ and $r_{\mathrm{d}}$ are the distance from the $\mathrm{X}$-ray source to the detector and the detector thickness. $a$ is the NP radius, $\theta$ is the Xray scattering angle, $\varphi$ is the Azimuthal angle with respect to the axis source-detector and $\lambda$ is the radiation wavelength. The differential cross section for the scattering of unpolarised radiation is given in Supplementary Note 4 .

In order to assess the impact of the NP size on the Mie scattering of X-rays, we simulated the Mie-scattering process for spherical $\mathrm{Bi}_{2} \mathrm{O}_{3}$ NPs with diameters $(d)$ of 20,40 and $100 \mathrm{~nm}$. The NP size is crucial for detector sensitivity as NPs in the quantum dot regime $(<10 \mathrm{~nm})$ lead to indirect X-ray detection ${ }^{34}$, while large nanoparticles $(\geq 100 \mathrm{~nm})$ reduce the extraction probability for charges generated within the NP and also reduce the differential scattering cross section as the particle size becomes very much greater than the X-ray wavelength ${ }^{31}$. These simulations do not take into consideration the effect of an ensemble of NPs, particle size distribution of the NPs, the formation of NP clusters, or deviations in the aspect ratio from a simple spherical geometry. Figure 6a shows the angular dependent differential cross sections for photon energies ranging from 1 to $30 \mathrm{keV}$ for $d=40 \mathrm{~nm}$ NPs, where a high scattering effect can be seen at small angles. Considering a simplistic scenario where the $\mathrm{Bi}_{2} \mathrm{O}_{3} \mathrm{NPs}$ are arranged in a periodic structure throughout the detector volume, an incident X-ray photon (on a NP) with energy of $8 \mathrm{keV}\left(E_{\mathrm{i}}\right)$ has a high scattering cross section within $2^{\circ}$ (Supplementary Figure 10 and Supplementary Note 5). Under elastic scattering this photon will be scattered by $\sim 45 \mathrm{NPs}$ within the detector volume. However, as Mie scattering is an inelastic process, the scattered photon will have a lower energy $\left(E_{s}\right)$ than $E_{\mathrm{i}}$. Based on the X-ray attenuation curve for $\mathrm{Bi}_{2} \mathrm{O}_{3}$, this results in the deposition of more energy (equivalent to $E_{\mathrm{s}}$ ) as the scattered photon interacts with a subsequent NP (Fig. 6b, c). Therefore, tuning the NP loading such that two NP scattering sites are placed in close proximity to each other enables a significant enhancement $(\times 100)$ in the X-ray path length due to the X-ray scattering process, and energy deposited even within layers that are dimensionally "thin" for X-ray detection (i.e. $<100 \mu \mathrm{m}$ ).

Following the above simulations, we proceeded to confirm the predicted enhancement in X-ray scattering through Grazing Incidence-Small Angle X-ray Scattering (GI-SAXS) for BHJ$\mathrm{Bi}_{2} \mathrm{O}_{3} \mathrm{NP}$ films (same composition) consisting of three different NP sizes $(d=20,40$ and $100 \mathrm{~nm})$ (characterization of the $\mathrm{Bi}_{2} \mathrm{O}_{3}$ NPs used in this study is given in Supplementary Figure 11a, c and Supplementary Note 6). The comparison between the simulation and experimental scattering (at $8 \mathrm{keV}$ ) is given in Fig. 6d. The GI-SAXS results are in good agreement with the predictions based on the Mie-scattering effects, with approximately an order of magnitude difference in X-ray scattering at angles $<0.75^{\circ}$ for the $d=20$ and $40 \mathrm{~nm} \mathrm{NP}$ dimensions. However, as the NP diameter increases, up to $100 \mathrm{~nm}$, the X-ray scattering is reduced by two orders of magnitude as compared to the $d=40 \mathrm{~nm}$ device. While this observation is not supported by the $d=100 \mathrm{~nm}$ simulation carried out for a single sphere, GI-SAXS analysis (Supplementary Figure 11b) indicates that the X-ray scattering in this film takes place from $\sim 15 \mathrm{~nm}$ sized features. This is indicative of the importance of optimum NP packing in these films to achieve the desired Miescattering effects.

In order to assess the impact of the Mie-scattering process on the detector sensitivity, X-ray detectors were fabricated using the three different NP sizes $(d=20,40$ and $100 \mathrm{~nm})$ under the $\mathrm{Bi}_{2} \mathrm{O}_{3}-40$ condition, and tested under a $50 \mathrm{kV}$ X-ray source (Fig. 6e, f). The $d=40 \mathrm{~nm} \mathrm{NP}$ detectors show a three times higher response compared to the $d=20$ and $100 \mathrm{~nm}$ NP devices, which is in good agreement with the enhanced X-ray scattering theoretically predicted for the $d=40 \mathrm{~nm}$ NPs. We note that while quantum mechanical effects due to nanoscopic features can also influence the scattering processes this would require more in-depth theoretical and experimental studies, which are outside the scope of this work.

\section{Discussion}

In conclusion, we have developed a hybrid 'inorganic in organic', direct transduction X-ray detector that delivers outstanding sensitivities of 1712 and $58 \mu \mathrm{CmGy}^{-1} \mathrm{~cm}^{-3}$ for soft and hard $\mathrm{X}$-rays respectively. Furthermore, flexible detectors also show a high sensitivity approaching $300 \mu \mathrm{CmGy}^{-1} \mathrm{~cm}^{-3}$, highlighting the promise of the technology for dosimetry and imaging in 
a

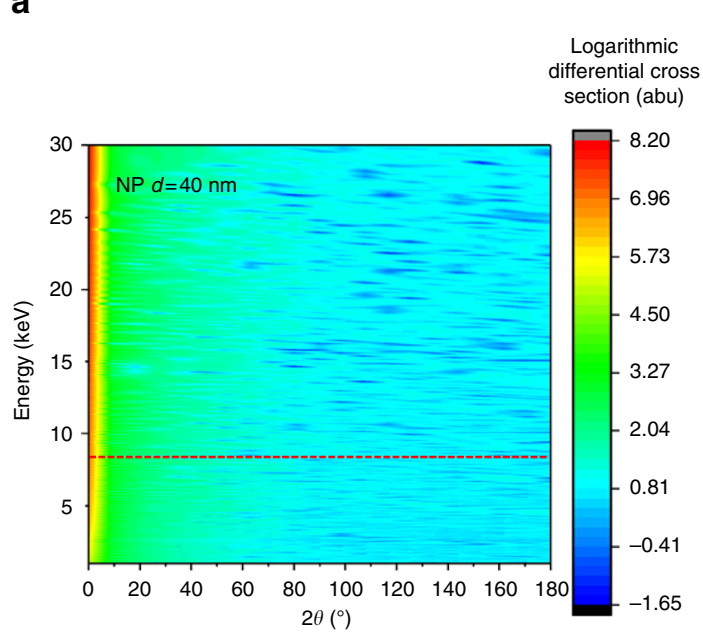

b

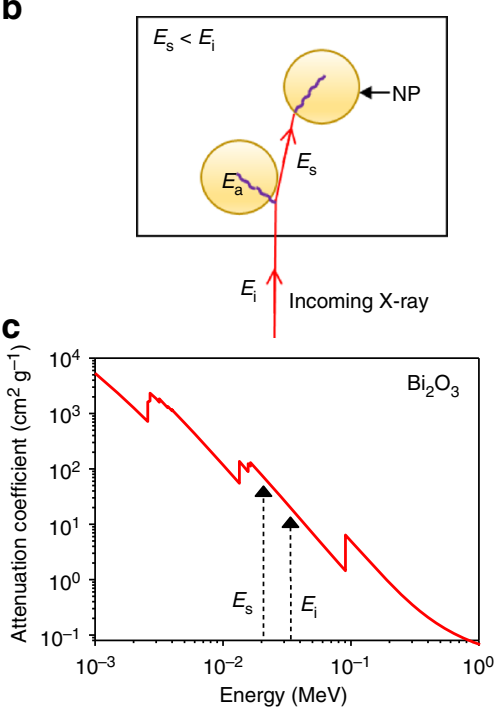

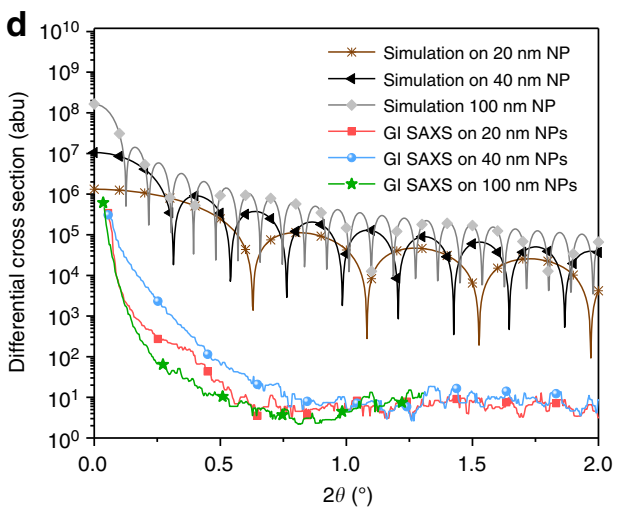

e

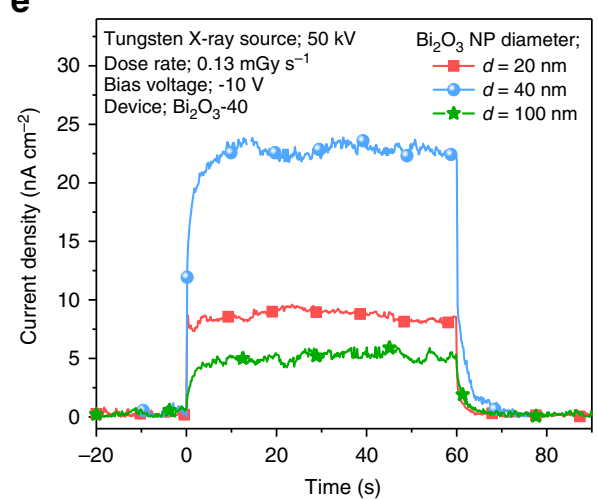

f

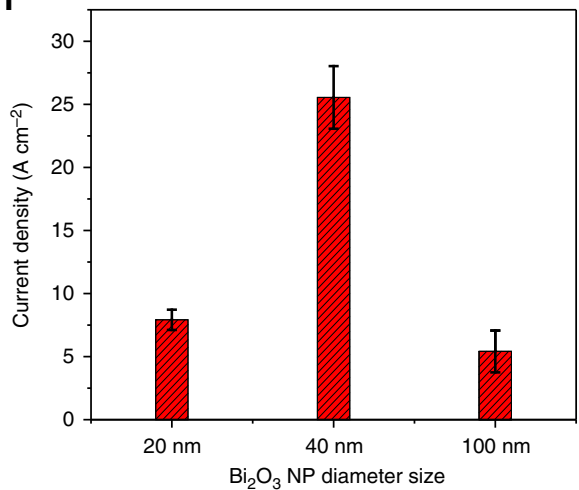

Fig. $6 \mathrm{X}$ ray scattering by nanoparticles. a Simulated differential cross sections for X-ray scattering from $\mathrm{Bi}_{2} \mathrm{O}_{3} \mathrm{NPs}$ with a diameter (d) of 40 nm. $\mathbf{b}$ The schematic of the inelastic Mie-scattering mechanism and $\mathbf{c}$ the mass attenuation coefficient curve of $\mathrm{Bi}_{2} \mathrm{O}_{3}$. Here, $E_{\mathrm{i}}, E_{\mathrm{a}}$ and $E_{\mathrm{s}}$ are the energy of the incident $\mathrm{X}$-ray photon, energy absorbed and the energy of the scattered photon, respectively. $\mathbf{d}$ The comparison of simulated differential cross section and extracted 1D data of experimental grazing incidence small angle X-ray scattering (GI-SAXS) at 8 keV energy for films with $d=20,40$ and $100 \mathrm{~nm}$ NPs. (The dotted line in a represents the extracted data at $8 \mathrm{keV}$.) e X-ray photocurrent response of the polymer diodes containing $\mathrm{Bi}_{2} \mathrm{O}_{3} \mathrm{NP}$ sizes of 20,40 and $100 \mathrm{~nm}$ and $\mathbf{f}$ the current density value with the spread for six detectors

non-planar architectures. The improved X-ray sensitivity is a result of impact ionization, and an enhanced path length due to Mie scattering and the efficient separation, and transport of these by the $\mathrm{BHJ}-\mathrm{NP}$ architecture resulting in high-charge collection efficiencies $(>60 \%)$. Based on this concept, a preliminary flat panel imager has also been demonstrated. The method of direct detection and imaging, combined with low cost, flexibility and scalability for large-area manufacture, improves on current solid state X-ray detector performance by 2-3 orders of magnitude, under low voltages, while delivering novel attributes suitable for a range of current and previously unexplored detection and imaging applications.

\section{Methods}

Materials. Regioregular poly(3-hexylthiophene-2,5-diyl) (P3HT, $40 \mathrm{mg}$, Rieke $4002 \mathrm{EE})$ and $[6,6]$-Phenyl $\mathrm{C}_{71}$ butyric acid methyl ester $\left(\mathrm{PC}_{70} \mathrm{BM}, 40 \mathrm{mg}, 99 \%\right.$ 
pure; Solenne) were added to dichlorobenzene $(1 \mathrm{ml})$ to produce a $\mathrm{P} 3 \mathrm{HT}: \mathrm{PC}_{70} \mathrm{BM}$ $\left(\mathrm{Bi}_{2} \mathrm{O}_{3}-0\right)$ solution. $\mathrm{Bi}_{2} \mathrm{O}_{3}$ nanoparticles ( $\beta$ phase with a tetragonal crystal structure; $38 \mathrm{~nm}$ diameter; surface area $18 \mathrm{~m}^{2} \mathrm{~g}^{-1}$; Alfa Aesar) were dispersed in P3HT: $\mathrm{PC}_{70} \mathrm{BM}$ solution to give $\mathrm{Bi}_{2} \mathrm{O}_{3}$ concentrations of $10\left(\mathrm{Bi}_{2} \mathrm{O}_{3}-10\right), 20\left(\mathrm{Bi}_{2} \mathrm{O}_{3}-20\right), 30$ $\left(\mathrm{Bi}_{2} \mathrm{O}_{3}-30\right), 40\left(\mathrm{Bi}_{2} \mathrm{O}_{3}-40\right), 50\left(\mathrm{Bi}_{2} \mathrm{O}_{3}-50\right), 60\left(\mathrm{Bi}_{2} \mathrm{O}_{3}-60\right), 70\left(\mathrm{Bi}_{2} \mathrm{O}_{3}-70\right)$ and 80 $\left(\mathrm{Bi}_{2} \mathrm{O}_{3}-80\right) \mathrm{mg} \mathrm{ml}^{-1}$.

Device fabrication. Rigid devices were fabricated on ITO $\left(\operatorname{In}_{2} \mathrm{O}_{3}\right.$ :Sn $)$ glass substrate $(15 \mathrm{~mm} \times 15 \mathrm{~mm}, 10 \Omega$ per square, Luminescence Technology Corp.) and flexible devices were fabricated on Kapton substrates $(15 \mathrm{~mm} \times 15 \mathrm{~mm}$, Dupont), with a patterned chromium $(\mathrm{Cr} ; 10 \mathrm{~nm}) / \mathrm{gold}(\mathrm{Au} ; 50 \mathrm{~nm})$ bilayer contact deposited as the anode using e-beam evaporation. A electron blocking and hole transporting Poly(3,4-ethylenedioxythiophene)-poly(styrenesulfonate) (PEDOT:PSS; P VP Al 4083; Heraeus) layer was spin coated in air (5000 rpm for $40 \mathrm{~s}$ ) and annealed at $150^{\circ} \mathrm{C}$ for $10 \mathrm{~min}$ to give a thickness of $40 \mathrm{~nm} . \mathrm{Bi}_{2} \mathrm{O}_{3}$ solutions $(90 \mu \mathrm{l})$ were then casted. Devices were annealed $\left(60^{\circ} \mathrm{C}\right)$ for $20-45 \mathrm{~min}$ in air, until a relatively dry layer was obtained. After the low temperature annealing process, all the devices were annealed at $140^{\circ} \mathrm{C}$ for $10 \mathrm{~min}$ in a $\mathrm{N}_{2}$ glove box (MBraun MB20G). Devices were kept under vacuum at a pressure of less than $3 \times 10^{-6} \mathrm{mbar}$ for $24 \mathrm{~h}$ to remove any residual solvent. This was followed by deposition of the hole blocking layer ( $5 \mathrm{~nm}$ thickness), 1-2,9-dimethyl-4,7diphenyl-1,10-phenanthroline (BCP; sublimed grade, Sigma Aldrich, 99.99\% purity) followed by deposition of an $\mathrm{Al}$ cathode $(\sim 150 \mathrm{~nm})$ by thermal evaporation. Device encapsulation was carried out with the deposition of UV light cure adhesive glue ( $20 \mu \mathrm{l}$ of Ossila Ltd) pressed with an encapsulation glass slide (Ossila) for the rigid devices, and a Kapton sheet for the flexible devices and the epoxy UV cured for $5 \mathrm{~min}$.

Electrical characterization. All the measurements are carried out in air at room temperature using an active device area of $0.68 \mathrm{~cm}^{2}$. A Keithley 2400 source measure unit was used to measure the current-voltage characteristics. The photocurrent performances of the devices were characterised in air using a $150 \mathrm{~W}$ Xe arc lamp solar simulator (Abet Technologies) fitted with an AM 1.5G filter. A reference Si cell (Newport, PVM 165) was used to adjust the intensity of the lamp to $100 \mathrm{~mW} \mathrm{~cm}^{-2}$.

X-ray irradiation and characterization. Six devices were tested for each X-ray irradiation measurement. Three different X-ray beam sources were employed for the characterisation of the detectors:

1. A tungsten tube X-ray beam (Seifert RP-149 Semiconductor Irradiation System) with accelerating voltage of $50 \mathrm{kV}$ under a dose-rate range of $27-131 \mu \mathrm{Gy} \mathrm{s}^{-1}$.

Dose calibration was completed using an ion beam chamber (Radcal; $10 \times 6-6$ ). A Keithley 2400 source measure unit was used for recording the electrical characteristics.

2. A $70 \mathrm{kV}$ X-ray source (Siemens MEGALIX Cat Plus 125/40/90, 124GW) with a tungsten anode. The X-ray spectrum was filtered with a 2.5 -mm-thick Al plate.

3. 6 and 15 MV X-rays from a multi-mode linear accelerator (Clinac iX, Varian USA) located at the Royal Surrey County Hospital. Dose rates from 100 to 400 cGy $\min ^{-1}$ were provided by the LINAC and a Keithley 2400 source measurement unit was used for recording the electrical characteristics of the devices.

Image readout and processing. An X-ray imager was fabricated using a method reported elsewhere ${ }^{7}$ under the device architecture of ITO/PEDOT:PSS/P3HT: $\mathrm{PC}_{70} \mathrm{BM}: \mathrm{Bi}_{2} \mathrm{O}_{3} / \mathrm{Au}$. The P3HT:PC $\mathrm{P}_{70} \mathrm{BM}: \mathrm{Bi}_{2} \mathrm{O}_{3}$ ratio is 1:1:1 (equivalent to $\mathrm{Bi}_{2} \mathrm{O}_{3}-40$ device) with an active layer thickness of $250 \mu \mathrm{m}$.

$\mathrm{X}$-ray beam source (2) was used for the characterisation.

Images were taken by custom-made driving and readout electronics with a commercial available readout IC (ROIC) (ISC9717 from Flir). The backplane of the imager consists of a Borosilicate glass substrate with an array of $256 \times 256$ a-Si:H TFTs with $98 \mu \mathrm{m}$ pixel pitch. The signal at the input was simultaneously integrated, amplified, low pass filtered and converted from analog to digital with a 14-bit converter. The integration time was $10 \mathrm{~ms}$ and the integrator feedback capacitance $C_{\mathrm{f}}$ was $4 \mathrm{pF}$. To eliminate fixed pattern noise and image inhomogeneity, a flat fielding has been performed.

GI-SAXS. Devices for GI-SAXS were fabricated as stated above, but with 20,38 and $100 \mathrm{~nm} \mathrm{Bi} \mathrm{O}_{3} \mathrm{NPs}$ in $\mathrm{Bi}_{2} \mathrm{O}_{3}-40$ devices. Measurements were completed on a XEUSS 2.0 (Xenocs, France) equipped with a $\mathrm{Cu} K_{\alpha}$ microfocus source and a Pilatus $300 \mathrm{k}$ detector (Dectris, Switzerland). The scattering vector $(q)$ range of the data was calibrated using a silver behenate standard material. The detector was positioned $2.495 \mathrm{~m}$ away from the sample to utilise the lowest $q$ range available. The sample was aligned such that the surface was in the centre of the beam and parallel with the beam. For the GI-SAXS measurements, the sample was tilted by $1^{\circ}$. This moved the specular reflection sufficiently far away in $q$ that the scattering from the particles on the surface could be measured. The scattering was recorded for $30 \mathrm{~min}$.

GI-WAXS. X-ray measurements were performed with a Xeuss 2.0 (XENOCS, France) system. The system is equipped with a MetalJet (Excillum, Sweden) liquid gallium source, providing a $9.24 \mathrm{keV} \mathrm{X-ray} \mathrm{beam} \mathrm{collimated} \mathrm{to} \mathrm{a} \mathrm{beam}$ spot of $400 \mu \mathrm{m}$ laterally at the sample position, measuring the full sample length. X-ray diffraction patterns were acquired with a Pilatus3R 1M 2D detector (Dectris, Switzerland) placed at $\sim 311 \mathrm{~mm}$ from the sample. The distance between the sample and the detector was measured using a silver behenate calibrant in transmission geometry. Samples were measured in GI-WAXS geometry at an incident angle of $0.3^{\circ}$ (calculated to probe the entire film thickness) under vacuum atmosphere. Diffraction images were then remapped from pixel to scattering vector coordinates with the calibration equations reported ${ }^{35}$ and by using MATLAB software.

SEM/AFM/EDX. SEM was carried out using a FEI Quanta 200F Environmental scanning electron microscope and AFM was carried out using a VEECO Dimension 3000 atomic force microscope. EDX analysis was carried out using an $\mathrm{x}$-act Oxford Instrument system coupled with the SEM.

Time-of-flight. Devices were fabricated as stated above, but with a $20 \mathrm{~nm}$ thick $\mathrm{Al}$ contact for irradiation through the $\mathrm{Al}$ (hole transport analysis). As an excitation source, a 6 ns-pulsed Nd:YAG laser (Quantel, $532 \mathrm{~nm}, 45 \mathrm{~mJ}$ ) was used, and the bias voltage was applied to the sample using a Keithley 2400 . The transient current was measured as the voltage drop over a load resistor $(10 \mathrm{k} \Omega)$ and recorded with an oscilloscope (Agilent infiniium $1 \mathrm{GHz}, 4 \mathrm{GSa} \mathrm{s}^{-1}$ )

Simulation. FLUKA, a Monte Carlo simulation programme designed for the interaction and transport of articles and nuclei in matter, was used for simulation of the X-rays interaction with the active material. In order to simulate the energy depletion of our devices, the geometry of the $\mathrm{P} 3 \mathrm{HT}: \mathrm{PC}_{70} \mathrm{BM} \mathrm{BHJ}$ with embedded $\mathrm{Bi}_{2} \mathrm{O}_{3}$ NPs (the thickness variation of the active layer was obtained experimentally) were modelled and irradiated with $50 \mathrm{kV} \mathrm{X}$-ray photons to be processed by the FLUKA programme. Mie-scattering differential cross section simulations were carried out using MATLAB software, using a Mie function.

Data availability. The data supporting the findings of this study is available at 6571337.

Received: 13 March 2018 Accepted: 27 June 2018

Published online: 26 July 2018

\section{References}

1. Milbrath, B. D. et al. Radiation detector materials: An overview. J. Mater. Res. 23, 2561-2581 (2008)

2. Zhao, W., Ji, W. G., Debrie, A. \& Rowlands, J. A. Imaging performance of amorphous selenium based flat-panel detectors for digital mammography: Characterization of a small area prototype detector. Med. Phys. 30, 254-263 (2003).

3. Mills, C. A. et al. Direct detection of $6 \mathrm{MV}$ X-rays from a medical linear accelerator using a semiconducting polymer diode. Phys. Med. Biol. 58, 4471-4482 (2013).

4. Podgorsak, E. B. Radiation oncology physics: a handbook for teachers and students. Br. J. Cancer 98, 1020 (2008).

5. Takahashi, T. \& Watanabe, S. Recent progress in CdTe and CdZnTe detectors IEEE Trans. Nucl. Sci. 48, 950-959 (2001).

6. Klauk, H. Organic Electronics: Materials, Manufacturing and Applications (Wiley-VCH, Weinheim, 2006)

7. Shrestha, S. et al. High-performance direct conversion X-ray detectors based on sintered hybrid lead triiodide perovskite wafers. Nat. Photonics 11, 436-440 (2017).

8. Basiricò, L. et al. Direct X-ray photoconversion in flexible organic thin film devices operated below 1 V. Nat. Commun. 7, 13063 (2016).

9. Kingsley, J. W., Pearson, A. J., Harris, L., Weston, S. J. \& Lidzey, D. G. Detecting 6MV X-rays using an organic photovoltaic device. Org. Electron. 10, 1170-1173 (2009).

10. Intaniwet, A., Mills, C. A., Shkunov, M., Sellin, P. J. \& Keddie, J. L. Heavy metallic oxide nanoparticles for enhanced sensitivity in semiconducting polymer x-ray detectors. Nanotechnology 23, 235502 (2012).

11. Ankah, G. N. et al. PbS quantum dot based hybrid-organic photodetectors for X-ray sensing. Org. Electron. 33, 201-206 (2016).

12. Büchele, P. et al. X-ray imaging with scintillator-sensitized hybrid organic photodetectors. Nat. Photonics 9, 843-848 (2015)

13. Yakunin, S. et al. Detection of gamma photons using solution-grown single crystals of hybrid lead halide perovskites. Nat. Photonics 10, 585-589 (2016).

14. Knoll, G. F. Radiation Detection and Measurement (John Wiley \& Sons, Hoboken, NJ, 2010).

15. Chiang, T.-Y., Wei, C.-K. \& Ding, S.-J. Effects of bismuth oxide on physicochemical properties and osteogenic activity of dicalcium silicate cements. J. Med. Biol. Eng. 34, 30-35 (2013) 
16. Gearba, R. I. et al. Quantifying interfacial electric fields and local crystallinity in polymer-fullerene bulk-heterojunction solar cells. Adv. Funct. Mater. 21, 2666-2673 (2011).

17. Carey, J. D., Forrest, R. D. \& Silva, S. R. P. Origin of electric field enhancement in field emission from amorphous carbon thin films. Appl. Phys. Lett. 78, 2339 (2001).

18. Amaratunga, G. A. J. \& Silva, S. R. P. Nitrogen containing hydrogenated amorphous carbon for thin-film field emission cathodes. Appl. Phys. Lett. 68, 2529 (1996).

19. Gelinck, G. H. et al. X-ray detector-on-plastic with high sensitivity using low cost, solution-processed organic photodiodes. IEEE Trans. Electron Devices 63, 197-204 (2016).

20. Ciavatti, A. et al. Dynamics of direct X-ray detection processes in high- $\mathrm{Z} \mathrm{Bi}_{2}$ $\mathrm{O}_{3}$ nanoparticles-loaded PFO polymer-based diodes. Appl. Phys. Lett. 111, 183301 (2017).

21. Wazzan, A. R. MOS (metal oxide semiconductor) physics and technology. Nucl. Technol. 74, 235-237 (1986).

22. Oehzelt, M. et al. Organic semiconductor density of states controls the energy level alignment at electrode interfaces. Nat. Commun. 5, 121-128 (2014).

23. Kim, T. et al. Flexible, highly efficient all-polymer solar cells. Nat. Commun. 6, 8547 (2015).

24. Mijnheer, B., Beddar, S., Izewska, J. \& Reft, C. In vivo dosimetry in external beam radiotherapy. Med. Phys. 40, 070903 (2013).

25. Kingsley, J. W., Weston, S. J. \& Lidzey, D. G. Stability of X-ray detectors based on organic photovoltaic devices. IEEE J. Sel. Top. Quantum Electron. 16, 1770-1775 (2010).

26. Thirimanne, H. M. et al. Charge funneling through metal electrode structuring for high-efficiency gains in polymer solar cells. Adv. Electron. Mater. 2 1600049 (2016).

27. Pivrikas, A., Sariciftci, N. S., Juška, G. \& Österbacka, R. A review of charge transport and recombination in polymer/fullerene organic solar cells. Prog. Photovolt. Res. Appl. 15, 677-696 (2007).

28. Karl, N. Charge carrier transport in organic semiconductors. Synth. Met. 133, 649-657 (2003).

29. Cowan, S. R., Roy, A. \& Heeger, A. J. Recombination in polymer-fullerene bulk heterojunction solar cells. Phys. Rev. B 82, 245207 (2010).

30. Juška, G. \& Arlauskas, K. Impact ionization and mobilities of charge carriers at high electric fields in amorphous selenium. Phys. Status Solidi 59, 389-393 (1980).

31. Lewkow, N. R. Scattering of Particles and Radiation in Astrophysical Environments (Springer International Publishing, New York, NY, 2016).

32. Snios, B., Lewkow, N. \& Kharchenko, V. Cometary emissions induced by scattering and fluorescence of solar X-rays. Astronomy \& Astrophysics 568, A80 (2014).

33. van de Hulst, H. C. Light Scattering by Small Particles (Dover Publications, Mineola, NY, 1981).

34. Burke, E. R., Dehaven, S. L. \& Williams, P. A. Scintillating quantum dots for imaging X-rays (SQDIX) for aircraft inspection. AIP Conference Proceedings 1706, 110007 (2016).

35. Lilliu, S. \& Dane, T. Reciprocal space mapping for dummies. Preprint at arXiv:1511.06224 (2015)

36. Mills, C. A., Intaniwet, A., Shkunov, M., Keddie, J. L. \& Sellin, P. J. Flexible radiation dosimeters incorporating semiconducting polymer thick films. Proc. SPIE 7449, 74491 (2009).

37. Intaniwet, A. et al. Characterization of thick film poly(triarylamine) semiconductor diodes for direct x-ray detection. J. Appl. Phys. 106, 064513 (2009).

38. Mills, C. A. et al. Enhanced X-ray detection sensitivity in semiconducting polymer diodes containing metallic nanoparticles. J. Phys. D Appl. Phys. 46, 275102 (2013).

39. Yakunin, S. et al. Detection of X-ray photons by solution-processed lead halide perovskites. Nat. Photonics 9, 444-449 (2015).

40. Wei, H. et al. Sensitive X-ray detectors made of methylammonium lead tribromide perovskite single crystals. Nat. Photonics 10, 333-339 (2016).

41. Lai, S. et al. A highly sensitive, direct X-ray detector based on a low-voltage organic field-effect transistor. Adv. Electron. Mater. 3, 1600409 (2017).

42. Kim, Y. C. et al. Printable organometallic perovskite enables large-area, lowdose X-ray imaging. Nature 550, 87-91 (2017).

43. Wei, W. et al. Monolithic integration of hybrid perovskite single crystals with heterogenous substrate for highly sensitive X-ray imaging. Nat. Photonics 11, 315-321 (2017).
44. Pan, W. et al. Cs2AgBiBr6 single-crystal X-ray detectors with a low detection limit. Nat. Photonics 11, 726-732 (2017).

45. Kasap, S. O. et al. X-ray sensitivity of photoconductors: application to stabilized a-Se. J. Phys. D Appl. Phys. 33, 2853-2865 (2000).

46. Won, J. H. et al. The X-ray sensitivity of semi-insulating polycrystalline CdZnTe thick films. Nucl. Instrum. Methods Phys. Res. Sect. A Accel. Spectrometers Detect. Assoc. Equip. 591, 206-208 (2008).

47. Greiffenberg, D., Fauler, A., Zwerger, A. \& Fiederle, M. Energy resolution and transport properties of CdTe-Timepix-Assemblies. J. Instrum. 6, C01058-C01058 (2011)

48. Oh, K. M. et al. Measurement of the electrical properties of a polycrystalline cadmium telluride for direct conversion flat panel x-ray detector. J. Instrum. 9 , P01010-P01010 (2014).

49. Starkenburg, D. J., Johns, P. M., Baciak, J. E., Nino, J. C. \& Xue, J. Thin film organic photodetectors for indirect X-ray detection demonstrating low dose rate sensitivity at low voltage operation. J. Appl. Phys. 122, 225502 (2017).

\section{Acknowledgements}

H.M.T., K.D.G.I.J., C.A.M. and S.R.P.S. gratefully acknowledge support for this work from the Leverhulme Trust through research project grant (No. RPG-2014-312). S.R.P.S and D.G.L. acknowledge Innovate UK (132376) and EPSRC for funding via research grants EP/L02263X/1 and EP/M025020/1, respectively. R.M.I.B. acknowledges support from the University of Surrey Overseas Research Scholarship/University Research Scholarship. We acknowledge P. Seller and S. Richards (Rutherford Appleton Laboratory) for their assistance with X-ray measurements. We thank A. Lohstroh (for assistance with X-ray measurements), V. Doukova (for obtaining DSC results), K. Snashall (for fabricating the flexible electrodes) and V. Stolojan (for useful discussions on EDX) (all University of Surrey). We thank Steven Huband and David Walker (University of Warwick) for obtaining GI-SAXS results. We thank Samuele Lilliu and Mejd Alsari for useful discussions.

\section{Author contributions}

H.M.T. and K.D.G.I.J. fabricated the devices, performed the experiments and analysed the data with C.A.M. and S.R.P.S. A.N. performed the LINAC experiment. H.M.T., S.F.T and J.E.H. fabricated, performed and analysed the X-ray imager. A.J.P. and D.G.L. performed GI-WAXS and analysed the data. R.M.I.B. performed and analysed the cross section SEM and EDX. A.K. performed the simulations. S.P. performed the X-ray measurements. C.A.M. and S.R.P.S. supervised the project. H.M.T., K.D.G.I.J., C.A.M. and S.R.P.S. wrote the manuscript.

\section{Additional information}

Supplementary Information accompanies this paper at https://doi.org/10.1038/s41467018-05301-6.

\section{Competing interests: The authors declare no competing interests.}

Reprints and permission information is available online at http://npg.nature.com/ reprintsandpermissions/

Publisher's note: Springer Nature remains neutral with regard to jurisdictional claims in published maps and institutional affiliations.

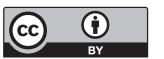

Open Access This article is licensed under a Creative Commons Attribution 4.0 International License, which permits use, sharing, adaptation, distribution and reproduction in any medium or format, as long as you give appropriate credit to the original author(s) and the source, provide a link to the Creative Commons license, and indicate if changes were made. The images or other third party material in this article are included in the article's Creative Commons license, unless indicated otherwise in a credit line to the material. If material is not included in the article's Creative Commons license and your intended use is not permitted by statutory regulation or exceeds the permitted use, you will need to obtain permission directly from the copyright holder. To view a copy of this license, visit http://creativecommons.org/ licenses/by/4.0/.

(C) The Author(s) 2018 